\title{
Trust But Verify: How Startups Can Build Healthy Strategic Alliances
}

\author{
John Friar (northeastern university) \\ Kimberly Eddleston (Northeastern University) \\ Tucker Marion (Northeastern University) \\ David Deeds (University of St. Thomas)
}

KEYWORDS: Innovation, Management, Alliance Management.

Outsourcing is growing trend for startups. Since new ventures often lack resources, they can augment their capabilities by working with other companies -- often much less expensive than hiring staff and bringing the function in house. Outsourcing also gives startups access to the same sophisticated capabilities that only larger companies once could afford.

Some entrepreneurs, in fact, have taken outsourcing to the extreme by becoming virtual organizations that outsource ALL functions (i.e. manufacturing of components, assembly, distribution, marketing, bookkeeping). By allowing entrepreneurs to focus on their core competency, outsourcing has become a common strategy that helps small businesses to grow and thrive. However, managing outsourcing relationships is not always easy and sometimes they can do more harm than good. We recently completed a longitudinal study that looked at the range of outsourcing relationships entrepreneurs utilize in developing their businesses. We discovered several triggers that can cause outsourcing relationships to go bad.

\section{From Contracting to Alliances}

Outsourcing covers a range of interorganizational relationships. The simplest form is contractual outsourcing. This typically is structured as a contract with a set deliverable for a fee. Entrepreneurs use these to solve specific problems by giving the outsourcing partners explicit specifications. An example would be to outsource the design of a product part that has a number of explicit characteristics. These are simple transactions and create buyer-vendor relationships. However, they can fail when the vendor performs inadequate work or when the entrepreneur provides

unclear or changing specifications. These failures can be a challenge to a startup but are usually recoverable since the entrepreneur can terminate the unsuccessful relationship and find a new vendor.

At the other extreme is a strategic alliance, where instead of remaining at arm's length the startup and the outsourcing company become partners. In these relationships, company boundaries tend to blur as each partner becomes actively involved in making strategic decisions. Over time, entrepreneurs can become dependent on their alliance partners, which can jeopardize the health of the startup and its original mission when the alliance partner takes the entrepreneur in a different direction. Furthermore, some alliance partnerships become so strong that entrepreneurs grow blind to their weaknesses and ignore warning signs that the partnership is damaging their business.

\section{What We Found}

In our study, we studied 14 new ventures over multiple years to investigate why entrepreneurs form outsourcing relationships and alliances, how those interorganizational relationships develop over time, and why some interorganizational relationships are more successful than others.Our findings revealed that the progression and management of interorganizational relationships impacted the performance of new ventures, and specifically the discovery, development and commercialization of an opportunity.

In particular, all of the new businesses in our study utilized simple contractual relationships to aid their new product development. In the early stages, those entrepreneurs who perceived their outsourcing partner 
as deficient or incapable discontinued the relationship. Those entrepreneurs who viewed their outsourcing partner as satisfactory and proficient, however, began to transform the interorganizational relationship into an alliance because competence-based trust had been established. In other words, because the entrepreneurs trusted that their outsourcing partner was competent, they allowed their relationship to become more integrated and interdependent.

\section{The Dangers of Trusting Too Much}

As this interdependency grew, the entrepreneurs began to turn more authority for decision-making over to the partners. We also found that as the alliance partner became more integrated into the new venture, a strong personal bond often formed between the entrepreneur and alliance partner. While these socioemotional bonds made some new ventures successful, they were disastrous for about $25 \%$ of the startups. The alliance relationship became so dependent on socioemotional bonds that it was destructive to the venture. Preserving the friendship that formed between the entrepreneur and alliance partner took precedence over achieving work goals. Additionally, most of these interorganizational relationships progressed from a transactional outsourcing relationship to an alliance without renegotiating the original agreement. No contractual agreements were ever revised; the parties never discussed any new terms or determined if the partner could adequately perform the extended work. The entrepreneurs seemed blind to their alliance partner's shortcomings and infractions.

For example, some entrepreneurs refused to believe that their alliance partner could not perform complex tasks for the new product's development since they had such a strong socioemotional bond with the partner and the partner had performed satisfactorily when initially contracted. Rather than terminate the relationship, these entrepreneurs continued to pay the alliance partner and some even extended their work responsibilities. Because of strong socioemotional bonds, many entrepreneurs trusted their alliance partner to make crucial business decisions and did not listen to employees' criticism of the partners performance. Over time, the alliance partner's authority became more entrenched and accepted in the new venture. When the socioemotional bonds supersede business obligations and role boundaries are blurred, we term the alliance as "enmeshed."

\section{Signs of a Troubled Relationship}

Symptoms of an enmeshed alliance are:

- The partners stopped having explicit understandings of what was expected of each other; contractual obligations were either no longer relevant or never identified.

- As socioemotional bonds strengthened, the entrepreneur became more reliant on the alliance partner, ceding decision-making authority to the partner.

- Even when problems occurred such as delays or quality issues, the entrepreneur would not discuss their dissatisfaction or set job requirements for the partner.

- The friendship between the entrepreneur and alliance partner began to matter more than business outcomes, blinding the entrepreneur to any signs of incompetence and poor performance.

\section{Recovering From an Enmeshed Alliance}

Although our study revealed that an enmeshed alliance can lead to a new venture's failure, about half of the new ventures in enmeshed alliances were able to recover. The entrepreneurs of these ventures had a moment of reckoning spurred by an imminent threat to the new venture that led the entrepreneur to identify incompetence and the intrusion of the alliance partner on their authority. For some entrepreneurs, this moment of clarify came when they were forced to infuse more capital into the business. Others finally realized that their alliance was hurting their new venture's progress when repeated problems with the alliance partner's work were acknowledged. Here are some lessons from the new ventures that recovered from enmeshed alliances as well as those that were able to develop and maintain successful alliances:

- Clearly communicate contractual obligations and be sure to update agreements as the relationship evolves. This establishes clear expectations, boundaries, and division of responsibilities.

- Make expectations explicit. Do not assume that your alliance partner knows what is expected from your business relationship. By establishing open communication you can quickly address any problems that arise and focus on business obligations. 
- Do not ignore signs of trouble by making excuses for lateness, cost overruns or poor quality. An entrepreneur needs to remain in charge, with the success of the business as the primary driver of decisions. While socioemotional bonds and the trust that ensues can certainly facilitate an alliance, they should not take precedence over business obligations.

\section{Conclusion}

Outsourcing has allowed new ventures to develop much more quickly and cheaply than by doing everything inhouse. When the initial outsourcing transactions are successful and competence-based trust is established, many of these interorganizational relationships will evolve into alliances. However, this evolution in collaboration can be dangerous if trust is based on the relationship rather than on the ability to do the job: when the entrepreneur allows socioemotional bonds with the alliance partner to supersede business obligations. As interorganizational relationships strengthen, most entrepreneurs fail to explicitly discuss new expectations, update contracts, and reevaluate the competence of the partner. But to prevent trouble and the development of an enmeshed alliance, entrepreneurs need to place business before friendship and regularly discuss expectations and obligations before misunderstandings arise. As such, entrepreneurs need to keep President Reagan's famous admonition in mind when dealing with alliance partners - "Trust but verify." 